\title{
Biofuel Toxicity and Mechanisms of Biofuel Tolerance in Three Model Cyanobacteria
}

Anne M. Ruffing and Christine A. Trahan 


\section{Abstract}

While recent studies have demonstrated direct photosynthetic production of biofuels via

14 engineered cyanobacteria, biofuel yields from cyanobacteria remain at low levels. As with

15 heterotrophic biofuel production, product toxicity is likely a limiting factor. Some mechanisms

16 of toxicity may be similar to those studied in common heterotrophic hosts; however, the

17 photosynthesis-dependent pathways for carbon fixation and energy production in cyanobacteria

18 present unique targets for biofuel toxicity. This study investigates biofuel toxicity for three

19 model cyanobacterial strains: Synechococcus elongatus PCC 7942, Synechocystis sp. PCC 6803,

20 and Synechococcus sp. PCC 7002. While cyanobacterial biofuel tolerances were generally lower

21 than that of heterotrophic hosts, the marine strain Synechococcus sp. PCC 7002 showed

22 increased tolerance to short chain alcohols, and long-chain biofuel products, such as fatty

23 alcohols, saturated free fatty acids, alkanes, and alkenes had minimal toxicity for all three

24 cyanobacteria. Targeted mutants were generated to explore natural mechanisms of biofuel

25 tolerance in cyanobacteria, such as cell membrane composition, reactive oxygen species

26 degradation, and efflux pumps. These mutants confirmed the influence of cell membrane

27 composition on cyanobacterial tolerance to short-chain alcohols. This study provides data to

28 guide both biofuel product and cyanobacterial host selection and further identifies potential

29 targets for improving biofuel tolerance in cyanobacteria.

30

31 Keywords: biofuel toxicity, cyanobacterial biofuel toxicity, biofuel tolerance, cyanobacterial

32 biofuel tolerance, cyanobacterial biofuels 


\section{Introduction}

Microbes can be engineered to produce a variety of potential fuel products with varying carbon chain lengths and chemical properties (Figure 1). In fact, cyanobacteria have been

36 successfully engineered to produce ethanol [1, 2], butanol [3, 4], isoprene [5, 6], squalene [7],

37 free fatty acids [8,9], fatty alcohols [10], and alkanes/alkenes [10, 11]. The productivities

38 associated with microbial synthesis of these biofuels, however, is often too low to meet

39 requirements for large-scale production. One of the major factors limiting high biofuel

40 productivity is product toxicity. Product toxicity must therefore be an important consideration

41 when selecting a cyanobacterial host and target biofuel product. Furthermore, mechanisms for

42 improving cyanobacterial biofuel tolerance may be important targets for genetic manipulation to 43 optimize biofuel production.

Attempts to engineer cyanobacteria for photosynthetic biofuel production have increased

45 dramatically within the past decade, and as these fuel-producing cyanobacteria are characterized, an increasing number of observations of biofuel toxicity are reported. While this is not

47 surprising, as biofuel toxicity has been a long-standing issue in heterotrophic biofuel production,

48 additional characterization and investigation of biofuel toxicity in cyanobacteria and

49 cyanobacterial biofuel tolerance is necessary to optimize biofuel production in these

50 photosynthetic hosts. Reduced cell growth was observed during ethanol and isobutanol

51 production in Synechocystis sp. PCC 6803 and Synechococcus elongatus PCC 7942 [2, 3], and

52 free fatty acid production resulted in reduced growth, decreased photosynthetic yield, reduced

53 chlorophyll-a, increased reactive oxygen species, changes in membrane composition, and

54 changes in gene expression in engineered S. elongatus PCC 7942 [9, 12]. Additionally, ethanol,

55 isobutanol, and hexane production in Synechocystis sp. PCC 6803 led to significant 
transcriptomic and proteomic responses, including changes in genes and proteins involved in

57 stress response, transport, cell envelope modification, cell mobility, and photosynthesis [13-17].

58 While some reduction in cell growth is expected as biofuel production consumes carbon

59 normally used for cell growth, these additional physiological effects indicate that biofuel production impacts the cyanobacterial host in a broad, systems-level manner.

To date, cyanobacterial biofuel tolerance has received little attention, particularly compared to the heterotrophic hosts Escherichia coli and Saccharomyces cerevisiae [18, 19].

63 Some earlier studies investigated the toxic effects of organic solvents on cyanobacterial growth 64 to determine the environmental impact of pollutants and the feasibility of using cyanobacteria in 65 aqueous-organic two-phase bioprocesses [20, 21]. However, the organic solvents tested in these 66 studies are not ideal biofuel targets and some of the model cyanobacterial strains were not 67 included in these toxicity tests. A more recent study investigated exogenous addition of low and 68 medium chain alcohols, acids, aldehydes, and alkanes to two model freshwater cyanobacteria, $S$. 69 elongatus PCC 7942 and Synechocystis sp. PCC 6803 [22]. This study found the potential 70 biofuel products to inhibit growth, with alcohols leading to the greatest inhibition. Moreover, 71 Synechocystis sp. PCC 6803 was found to generally have a higher biofuel tolerance compared to 72 S. elongatus PCC 7942. While this study provides important information on biofuel toxicity and 73 cyanobacterial tolerance, it does not cover key aspects, including the toxicity and tolerance to 74 longer chain biofuel products $(\mathrm{C} 16-\mathrm{C} 18)$ which are more likely to be metabolically produced in 75 cyanobacteria, the tolerance of marine cyanobacterial strains such as the model cyanobacterium 76 Synechococcus sp. PCC 7002, and the identification of potential biofuel tolerance mechanisms in 77 cyanobacteria. 
While mechanisms of biofuel toxicity for cyanobacteria have yet to be identified,

79 mechanisms of toxicity in heterotrophic, Gram-negative bacteria such as E. coli have been

80

81

82

83

84

85

86

87

88 extensively studied. The primary mechanism of toxicity for biofuels initiates through their interaction with and integration into cellular membranes $[23,24]$. This biofuel-membrane interaction alters membrane fluidity and permeability, ultimately leading to inhibition of membrane-associated enzymes, disruption of the electron transport chain and oxidative phosphorylation, dissipation of the proton motive force, loss of intracellular $\mathrm{pH}$ homeostasis, and possibly even cell lysis $[18,24,25]$. Biofuels with long carbon chains (generally greater than C12) are typically less toxic to microbes [26], and unsaturated free fatty acids have greater toxicity than their saturated counterparts, presumably due to lipid peroxidation [25]. Additional information about biofuel toxicity and tolerance can be found in recent reviews [26-30].

In this study, we aim to advance and expand the current knowledge of cyanobacterial biofuel toxicity and tolerance to help inform the selection of cyanobacterial hosts and product targets for biofuel strain development efforts. We investigate three model cyanobacteria strains, freshwater strains S. elongatus PCC 7942 and Synechocystis sp. PCC 6803 and a marine strain Synechococcus sp. PCC 7002. The inclusion of a marine cyanobacterium is important, as it will likely have different membrane composition and properties compared to the freshwater species. Moreover, cellular responses to organic solvents and biofuels are often similar to other stress responses [29]; therefore, Synechococcus sp. PCC 7002, with its high light, high temperature, and high salt tolerances, may also have high biofuel tolerance $[31,32]$. The biofuel products investigated in this study include those readily produced from the cyanobacterial metabolism (Figure 1): ethanol, isobutanol, 1-hexadecanol, $\alpha$-linolenic acid (unsaturated FFA), palmitic and stearic acids (saturated FFAs), pentadecane, and 1-heptadecene. These long-chain biofuel targets 
101 (C15 - C18) are likely biofuel targets based on the fatty acid composition of cyanobacterial 102 membranes, which are predominantly C16 and C18 FAs [33]. This study analyzes the growth 103 inhibition and physiological effects of biofuel addition to cyanobacterial cultures along with a

104 preliminary investigation into three possible mechanisms of natural biofuel tolerance in 105 cyanobacteria: cell membrane composition, reactive oxygen species degradation, and efflux 106 pump activity.

\section{2. Results and Discussion}

\subsection{Cyanobacterial Growth Inhibition and Physiological Effects of Exogenous Biofuels}

As described in the Introduction, three model cyanobacterial species were characterized for toxic or inhibitory effects upon exogenous addition of potential metabolically-produced fuels

111 or fuel precursors (collectively referred to as 'biofuels' in the subsequent text) (Figure 1). For

112 each target biofuel, the concentration of biofuel was increased until either (1) complete growth

113 inhibition was observed 5 days after inoculation in the biofuel-spiked medium or (2) the 114 concentration exceeded the solubility limit of the biofuel in aqueous solution. Biofuel solubility 115 was particularly problematic for targets containing long chain hydrocarbons (1-hexadecanol, 116 linolenic acid, palmitic acid, stearic acid, pentadecane, and 1-heptadecene). The experimental or 117 predicted aqueous solubilities for each biofuel are listed in the Supplemental File, Table S1. Due 118 to difficulties in obtaining accurate concentrations at the low solubility limits, the tested 119 concentration ranges are often well above the solubility limits. Due to the volatile nature of the 120 short-chain biofuel products, namely ethanol and isobutanol, evaporation of the biofuel is likely 121 to occur under the cultivation conditions of $30^{\circ} \mathrm{C}$. As this inherent property is difficult to control, 122 the reader should note that the concentrations reported in this study are initial concentrations of 123 the biofuel in the culture. 
125 alcohols, ethanol and isobutanol, had inhibitory effects on the growth of all three strains within 5

126 days of biofuel addition. Of the three model strains, Synechococcus sp. PCC 7002 was most

127 tolerant of short chain alcohols, showing some growth at ethanol concentrations as high as $0.6 \mathrm{M}$ 128 and isobutanol concentrations as high as $0.08 \mathrm{M}$ (Figure 2A,B). On the other hand, S. elongatus

129 PCC 7942 was the least tolerant with growth at ethanol concentrations as high as $0.2 \mathrm{M}$ and 130 isobutanol concentration as high as $0.02 \mathrm{M}$. Overall, cyanobacterial ethanol and isobutanol 131 tolerance is slightly lower than that of Escherichia coli, which has native tolerances up to $1.03 \mathrm{M}$ 132 and $0.13 \mathrm{M}$, respectively $[18,34]$. While these short chain alcohols proved toxic to 133 cyanobacteria, the long-chain fatty alcohol, 1-hexadecanol, did not lead to any observable 134 growth inhibition for all 3 cyanobacterial strains under the concentrations tested (Figure 2C). 135 Due to the low solubility of 1-hexadecanol, concentrations higher than $0.75 \mu \mathrm{M}$ were not tested. 136 While it's anticipated that higher concentrations would not generate a toxic effect due to phase 137 separation of 1-hexadecanol, this still remains to be investigated. saturation. Saturated FFAs, palmitic (16:0) and stearic (18:0) acids, did not have an inhibitory 140 effect on any of the model cyanobacterial strains (Figure 2E,F); however, the polyunsaturated 141 FFA, $\alpha$-linolenic acid (18:3), reduced cell growth in all 3 cyanobacteria (Figure 2D).

142 Interestingly, Synechococcus sp. PCC 7002 was the most susceptible to $\alpha$-linolenic acid (LA) 143 toxicity, with complete inhibition at $25 \mu \mathrm{M}$ of LA, while Synechocystis sp. PCC 6803 was the 144 most tolerant, showing no significant effect on growth at $25 \mu \mathrm{M}$ of LA. Growth of both 145 Synechocystis sp. PCC 6803 and S. elongatus PCC 7942 was completely inhibited at $50 \mu \mathrm{M}$ of 146 LA. These results suggest that different mechanisms contribute to short-chain alcohol and 
147 unsaturated FFA tolerances in cyanobacteria. Furthermore, this illustrates that biofuel toxicity

148 may be observed at concentrations exceeding the solubility limit of the biofuel, as growth

149 inhibition of S. elongatus PCC 7942 and Synechocystis sp. PCC 6803 is only observed at

150 concentrations (10 and $50 \mu \mathrm{M}$, Figure 2D) exceeding the predicted solubility limit for LA (0.444

$151 \mu \mathrm{M}$, Supplemental File - Table S1).

152 The long-chain alkane, pentadecane (C15), and long-chain alkene, 1-heptadecene

153 (C17:1), showed no significant inhibitory effect on Synechocystis sp. PCC 6803 and

154 Synechococcus sp. PCC 7002, even at concentrations exceeding the solubility limits by 10 to 11

155 orders of magnitude (Figure 2G,H). S. elongatus PCC 7942, however, had a 92\% reduction in

156 growth at pentadecane concentrations exceeding $50 \mathrm{mM}$ (Figure $2 \mathrm{G}$ ) and a $15 \%$ reduction in

157 growth at $100 \mathrm{mM}$ of 1-heptadecane (Figure 2H). These results are in agreement with previous

158 toxicity studies using undecane (C11), which showed growth inhibition of S. elongatus PCC

1597942 at 51 and $96 \mathrm{mM}$ and only slight inhibition of Synechocystis sp. PCC 6803 at the same

160 concentrations [22]. Again, these results confirm that toxicity effects may be observed at

161 concentrations exceeding the solubility limit.

162 In addition to biofuel-induced growth inhibition, photosynthetic yield measurements were

163 also taken as an indication of the overall cell health of the cyanobacteria (Figure 3) [35]. In

164 general, the photosynthetic yield measurement correlated with growth inhibition, with reduced

165 photosynthetic yields accompanying reduced growth. One exception was the photosynthetic

166 yield of Synechococcus sp. PCC 7002 in response to 1-heptadecene (Figure 3H). The growth of

167 Synechococcus sp. PCC 7002 was unaffected by all concentrations of 1-heptadecene tested;

168 however, photosynthetic yield was significantly decreased in Synechococcus sp. PCC 7002

169 cultures with the addition of 50 and $100 \mathrm{mM}$ of 1-heptadecene. The reduced photosynthetic yield 

173 inhibition in these cultures.

174 of cyanobacterial cultures.

measurements indicate a reduced efficiency of electron transport through photosystem II. As photosynthesis drives carbon fixation and energy production, it is surprising that these cultures do not also show reduced growth. It is possible that later time points would show growth

\subsection{Cyanobacterial Ethanol Tolerances of Exponential Phase Cultures}

During microbial biofuel production, biofuel accumulation generally correlates with cell growth, reaching high levels only in the late exponential or stationary phases [9]. Therefore, it is important to not only test growth inhibition but to also investigate the tolerance of exponential phase cultures to biofuel addition. To this end, ethanol was added to cyanobacterial cultures during the mid-exponential growth phase $\left(\mathrm{OD}_{730} \sim 0.3\right)$ at various concentrations, with higher ethanol concentrations for Synechococcus sp. PCC 7002 due to its improved tolerance. Compared to the control, with no ethanol addition, all three strains showed growth inhibition (Figure 4A,D,G). Again, the photosynthetic yield measurements correlated with the growth measurements (Figure 4B,E,H), but the photosynthetic yield measurements showed a faster response, with $\mathrm{F}_{\mathrm{v}}{ }^{\prime} / \mathrm{F}_{\mathrm{m}}$ ' measurements near zero within 10 hours after ethanol addition. There is one notable exception, however; the photosynthetic yield measurements for Synechocystis sp. PCC 6803 with $0.5 \mathrm{M}$ ethanol remained nearly as high as the no ethanol control after a slight dip in the first few hours following ethanol addition (Figure 4E). Interestingly, this high photosynthetic yield did not correlate with improved growth (Figure 4D), suggesting that the excess electrons are dissipated or utilized for a function other than cell growth. This result cautions against the sole reliance on photosynthetic yield measurements to determine cell health 
As described in the Introduction, one of the main mechanisms for biofuel toxicity is

reported to be the disruption of the cell membrane. To determine whether ethanol addition disrupts the cell membrane, the membrane impermeable fluorescent dye, SYTOX, was used to measure cell membrane permeability (Figure 4C,F,I). All three cyanobacterial strains showed increased membrane permeability with the addition of ethanol, with the percentage of membrane-permeable cells increasing with increasing ethanol concentrations. However, ethanol concentrations as high as $0.5 \mathrm{M}$ do not have a significant effect on membrane permeability in the three cyanobacteria despite the significant reduction in cell growth and photosynthetic yield (with the exception of Synechocystis sp. PCC 6803) at this ethanol concentration. Unexpectedly, Synechocystis sp. PCC 6803 had a lower percentage of membrane-permeable cells (a maximum of $51 \%$, Figure 4F - green diamonds) compared to the more ethanol resistant Synechococcus sp. PCC 7002 (99\% at the same time point for the same ethanol concentration, Figure 4I - blue triangles). Overall, these results suggest that membrane permeability is increased by ethanol addition, but that the level of permeability does not directly correlate with the inhibition of growth or reduction in photosynthetic yield.

\subsection{Cell Membrane Composition Influences Cyanobacterial Biofuel Tolerance}

In addition to permeabilizing the membrane, biofuels are also predicted to intercalate within cellular membranes, affecting membrane fluidity and the activity membrane-associated enzymes. In cyanobacteria, membrane-associated enzymes are not only responsible for the transport and export of nutrients and metabolites, they also generate cellular energy and reducing equivalents via photosynthesis in the intracellular thylakoid membranes. Based on this possible mechanism of toxicity, the chemical composition of the cell and thylakoid membranes may play an important role in cyanobacterial biofuel tolerance. Both S. elongatus PCC 7942 and 
215

216

217

218

219

220

221

222

223

224

225

226

227

228

229

230

231

232

233

234

235

236

237

Synechocystis sp. PCC 6803 are freshwater strains which may be expected to have similar membrane compositions, while the marine strain Synechococcus sp. PCC 7002 may have a unique membrane composition to allow for its higher salt tolerance.

To investigate changes in the chemical composition of membranes among the three strains, lipids were extracted from late exponential phase cultures and analyzed using ESI-MS. Significant differences in the degree of saturation of membrane lipids were measured between the three cyanobacteria (Table 1). S. elongatus PCC 7942 had predominantly monounsaturated lipid molecules (74.3\%) while Synechocystis sp. PCC 6803 had a high level of tri-unsaturated lipids (63.1\%) and Synechococcus sp. PCC 7002 had a distribution of mono (21.2\%), di (27.3\%) and tri $(39.7 \%)$-unsaturated lipids. Previous studies suggest that microbial salt tolerance can be improved by decreasing membrane viscosity [36]. Therefore, the lower degree of saturation of membrane lipids in Synechococcus sp. PCC 7002 may contribute to both the salt and short-chain alcohol tolerances of this strain compared to S. elongatus PCC 7942, yet this does not explain the lower salt and short-chain alcohol tolerances of Synechocystis sp. PCC 6803 in comparison to Synechococcus sp. PCC 7002. The lipid analysis presented in Table 1 is a whole cell analysis, including both cell and thylakoid lipids. In this analysis, the thylakoid lipids accounted for $94.7-$ $99.6 \%$ of the total signal, with the cell membrane lipids comprising only $0.4-5.3 \%$ of the signal. As the thylakoids membranes are intracellular, their composition may differ from the composition of the inner and outer cell membranes. While the signals for phosphatidylglycerol (PG), a major component of the cell membrane, are too low and variable to draw statistically significant conclusions, S. elongatus PCC 7942 had primarily monounsaturated signal while Synechococcus sp. PCC 7002 had mono and di-unsaturated signals, and PG signals from Synechocystis sp. PCC 6803 were too low for detectable signal above 1\% of the total. Therefore, 
238 although thylakoid and cell membrane biosynthesis utilize the same pathway for acyl-ACP

239 provision, chemical variations in fatty acid composition between these membranes may explain

240 why Synechocystis sp. PCC 6803 does not have higher ethanol tolerance.

241 Comparative genomics using the three model cyanobacterial strains was used to identify

242 desaturases that may contribute to the observed differences in the degree of membrane saturation

243 (Table 2). The number of desaturase genes in the genome generally correlates with the measured 244 degree of saturation $(7942<6803<7002)$. Both Synechocystis sp. PCC 6803 and

245 Synechococcus sp. PCC 7002 have a significantly greater number of desaturases within their 246 genomes compared to S. elongatus PCC 7942. Synechococcus sp. PCC 7002, the most ethanol

247 tolerant of all 3 strains, has two desaturases unique to its genome, desE (SYNPCC7002_A2833)

248 and $\operatorname{des} F$ (SYNPCC7002_A1989). These two desaturase genes along with desB

249 (SYNPCC7002_A0159), a desaturase shown to be important for low temperature tolerance [37],

250 were targeted for gene knockout in Synechococcus sp. PCC 7002 to assess their role in ethanol

251 tolerance. No significant change in ethanol tolerance was observed for the $\operatorname{des} E$ and $\operatorname{des} F$

252 mutants (7002 $\Delta 2833$ and $7002 \Delta 1989$ in Figure 5A); however, ethanol tolerance was reduced in

253 the $\operatorname{des} B$ mutant $(7002 \Delta 0159)$ at a concentration of $0.5 \mathrm{M}$ ethanol. This suggests that the degree

254 of saturation of membrane lipids may play a role in short-chain alcohol tolerance. It is unlikely

255 that this is the sole mechanism of short-chain alcohol tolerance, as $\operatorname{des} B$ gene knockout did not

256 lead to a drastic reduction in ethanol tolerance and Synechocystis sp. PCC 6803 also contains

$257 \operatorname{des} B$ but has lower short-chain alcohol tolerance.

$258 \quad 2.3$ Reactive Oxygen Species and Biofuel Toxicity

259 Generally, microbes under stress conditions have been shown to have high levels of 260 reactive oxygen species (ROS). The ROS themselves can be toxic to the cell, leading to lipid 
261 peroxidation as well as protein and DNA damage [38]. It is likely that biofuel stress also leads to

262 ROS generation, which may contribute to the observed toxicity. In fact, the reduction of ROS

263 accumulation by overexpression of sigma factor SigB improved butanol tolerance in

264 Synechocystis sp. PCC 6803 [39]. Our attempts to measure ROS levels in S. elongatus PCC 7942

265 and Synechocystis sp. PCC 6803 using a fluorescent ROS stain (2,7-dichloro fluorescein

266 diacetate $-\mathrm{H}_{2}$ DCFDA) in response to ethanol addition were largely unsuccessful due to high

267 variability; however, the addition of ethanol to cultures of Synechococcus sp. PCC 7002 resulted

268 in statistically significant increases in the percentage ROS-positive cells (up to $60 \pm 33 \%$ )

269 compared to the control with no ethanol addition $(1.4 \pm 0.63 \%)$. Furthermore, our previous work

270 investigating FFA production in engineered strains of S. elongatus PCC 7942 showed elevated

271 ROS levels in the FFA-producing strains relative to the wild type (cite). This data indicates that

272 ROS generation may be a contributing factor in biofuel toxicity.

273 Comparative genomics analysis of ROS-degrading proteins did not reveal any significant

274 genomic differences between the three cyanobacterial strains (Table 2). All three strains have

275 approximately the same number of ROS-degrading protein genes and only a few of these genes

276 are unique to a particular species. To investigate whether ROS-degrading proteins contribute to

277 biofuel tolerance, S. elongatus PCC 7942 was engineered to overexpress four ROS-degrading

278 proteins: glutathione peroxidase (Synpcc7942_1214), catalase/peroxidase HPI

279 (Synpcc7942_1656), glutathione peroxidase (Synpcc7942_0437), and superoxide dismutase

280 (Synpcc7942_0801). S. elongatus PCC 7942 was selected as the host for ROS-degrading protein

281 overexpression, as this strain was the most sensitive to ethanol. One of the target genes

282 (Synpcc7942_0437) does not have a close homolog in the other two cyanobacterial strains

283 (Table 2), while the other three targets have predicted homologs. The ethanol tolerances of all 
284 four ROS-degrading protein overexpression mutants of S. elongatus PCC 7942 were very similar

285 to that of the control strain (Figure 5B), suggesting that while ROS levels may be elevated in

286 response to biofuel addition, they are not a significant contributing factor to biofuel toxicity.

$287 \quad 2.4$ Do Efflux Pumps Contribute to Cyanobacterial Biofuel Tolerance?

288

Previous studies have shown that efflux pump proteins can play a pivotal role in biofuel

289 tolerance for E. coli [28]. Genomic analysis of predicted efflux pump protein genes in the three

290 model cyanobacteria indicates that cyanobacteria possess numerous efflux pump proteins, yet the

291 distribution of efflux pump proteins among the three strains is quite similar in both number and

292 predicted function (Table 2). As a preliminary investigation of the role of efflux pump proteins in

293 ethanol tolerance, several efflux pump protein genes were targeted for gene knockout in

294 Synechococcus sp. PCC 7002: a multidrug efflux transporter (SYNPCC7002_A0719), an outer

295 membrane efflux protein (SYNPCC7002_A0585), and a hydrophobe/amphiphile efflux-1

296 (HAE1) family protein (SYNPCC7002_A1013). SYNPCC7002_A1013 is a homolog of the

297 AcrB protein of $E$. coli, which is a component of the TolC-AcrAB efflux pump involved in

298 solvent tolerance and FFA export [28, 40]. The other two targets, SYNPCC7002_A0719 and

299 SYNPCC7002_A0585, have homologs in S. elongatus PCC 7942 and Synechocystis sp. PCC

3006803 , but these homologs have low amino acid sequence identity with the Synechococcus sp.

301 PCC 7002 targets (37.48-55.03\%) and are annotated as hypothetical proteins. Hence, these two

302 efflux pump genes in Synechococcus sp. PCC 7002 may contribute to its improved ethanol

303 tolerance relative to the other cyanobacteria. All three efflux pump gene mutants $(7002 \Delta 0719$,

$3047002 \Delta 0585$, and 7002 $\Delta 1013$ ) showed ethanol tolerances similar to the wild type (Figure 5C).

305 While this preliminary investigation did not identify an efflux pump protein involved in biofuel 
tolerance, further investigation is necessary to rule out the contribution of efflux pump proteins to cyanobacterial biofuel tolerance.

\section{Conclusions}

For cyanobacterial biofuel production, there are many decisions which can affect biofuel productivity, such as selection of the fuel target and host strain selection. Biofuel targets have

311 variable toxic effects on the host, and the host strain may have variable tolerance to each biofuel.

312 The results of this study provide some guidance for these critical decisions. Long-chain

313 alcohols, saturated FFAs, and alkanes/alkenes were found to have minimal effects on

314 cyanobacterial growth and physiology. Therefore, long-chain alcohols and alkanes/alkenes may

315 be good biofuel targets from a toxicity perspective. As the degree of saturation cannot be

316 controlled for FFAs, it's likely that FFA production will have toxic effects on the cyanobacterial

317 host. Indeed, this was observed previously during FFA production in S. elongatus PCC 7942 [9].

318 If toxic biofuel products are desirable targets for production, judicial host selection can help to

319 minimize the detrimental impact on productivity. Based on the growth inhibition studies

320 conducted in this work, Synechococcus sp. PCC 7002 should be a good host for short-chain

321 alcohol production while Synechocystis sp. PCC 6803 is a good option for FFA production. Both

322 Synechococcus sp. PCC 7002 and Synechocystis sp. PCC 6803 should be good hosts for alkane

323 production due to their higher tolerances compared to S. elongatus PCC 7942. By selecting

324 biofuel targets with low toxicity and cyanobacterial hosts with high biofuel tolerance, biofuel

325 productivities should improve.

326 It is essential to interpret the results and conclusions of this study within the confines of

327 the experimental parameters. One important caveat in the interpretation and application of the

328 results in this study is that only extracellular biofuel toxicity was tested, while cyanobacterial 
biofuel production will occur intracellularly. This distinction can have significant implications. For instance, a cyanobacterium may show high tolerance of an extracellular biofuel due to cell membrane properties which do not allow the biofuel to enter into the cell. When produced intracellularly, the same biofuel may have highly toxic effects. This was illustrated with FFA production in E. coli, whereby exogenous biofuel addition had minimal toxic effects and intracellular FFA production led to significant reductions in cell growth [41]. Additionally, ethanol production at the level of approximately $12.5 \mathrm{mM}$ led to nearly a $60 \%$ reduction in cell growth of Synechocystis sp. PCC 6803 [2], while exogenous ethanol addition would require an ethanol concentration of greater than $200 \mathrm{mM}$ according to the growth inhibition results of this study. A second caveat is that while biofuel toxicity can significantly impact productivity, it is certainly not the only factor to consider when selecting the biofuel target and cyanobacterial host. Cell growth, carbon flux through the biofuel pathway, energetic requirements, and cofactor requirements will also affect cyanobacterial biofuel productivities. These factors, therefore, should also be analyzed when optimizing productivity.

In addition to providing guidance regarding biofuel target and cyanobacterial host selection, this work investigated several possible mechanisms of cyanobacterial biofuel tolerance, including cell membrane composition, ROS generation, and efflux pump proteins. The lower ethanol tolerance of the desB mutant of Synechococcus sp. PCC 7002 confirms that cell membrane composition plays a role in short-chain alcohol tolerance. However, the ethanol tolerance of the $\operatorname{des} B$ mutant was not greatly reduced, showing complete growth inhibition at an ethanol concentration of $0.5 \mathrm{M}$, compared to $0.6 \mathrm{M}$ for the wild type. Therefore, other molecular mechanisms likely contribute to cyanobacterial biofuel tolerance. Additional investigation into these mechanisms will not only increase our understanding of biofuel tolerance, it will also 
352 identify potential metabolic engineering targets and strategies for improving cyanobacterial host

353 tolerance. This study, along with the previous investigation into cyanobacterial biofuel tolerance 354 [22], provide a good basis for further exploration of this important factor in the development of 355 cyanobacterial biofuel production.

357 4. Materials and Methods

\subsection{Materials}

Chemicals used in this study were purchased from Acros Organics $\left(\mathrm{Na}_{2} \mathrm{MoO}_{4} \cdot 2 \mathrm{H}_{2} \mathrm{O}\right.$, $360 \mathrm{Co}\left(\mathrm{NO}_{3}\right)_{2} \bullet 6 \mathrm{H}_{2} \mathrm{O}$ ), $\mathrm{BD}$ (agar), MP Biomedicals (ferric ammonium citrate, $\mathrm{ZnSO}_{4} \bullet 7 \mathrm{H}_{2} \mathrm{O}, \mathrm{CuSO}_{4}$

$\left.361 \cdot 5 \mathrm{H}_{2} \mathrm{O}\right)$, Fisher Scientific $\left(\mathrm{Na}_{2} \mathrm{CO}_{3}\right.$, agarose, tris-acetate-EDTA, $\mathrm{NaCl}, \mathrm{MgSO}_{4} \bullet 7 \mathrm{H}_{2} \mathrm{O}, \mathrm{KCl}$, $362 \mathrm{NaNO}_{3}$, tris base, $\mathrm{H}_{3} \mathrm{BO}_{3}$, sodium thiosulfate pentahydrate, and kanamycin monosulfate), Gold 363 Technology (IPTB) and Sigma-Aldrich $\left(\mathrm{Na}_{2} \mathrm{EDTA}, \mathrm{CaCl}_{2} \bullet 2 \mathrm{H}_{2} \mathrm{O}, \mathrm{KH}_{2} \mathrm{PO}_{4}\right.$, vitamin $\mathrm{B} 12, \mathrm{FeCl}_{3}$ $364 \cdot 6 \mathrm{H}_{2} \mathrm{O}, \mathrm{MnCl}_{2} \bullet 4 \mathrm{H}_{2} \mathrm{O}, \mathrm{ZnCl}_{2}, \mathrm{CoCl}_{2} \bullet 6 \mathrm{H}_{2} \mathrm{O}$, and spectinomycin dihydrochloride pentahydrate). 365 Primers were synthesized by Integrated DNA Technologies (IDT). DNA purifications were 366 performed using the Plasmid Miniprep, DNA Clean \& Concentrator, and Gel DNA Recovery 367 kits from Zymo Research. Restriction enzymes, DNA polymerases, and ligases were purchased 368 from New England Biolabs. Suppliers of all other materials used in this study are described 369 below.

\subsection{Bacterial Strains and Growth Conditions}

Three model strains of cyanobacteria were analyzed for biofuel tolerance, including two

372 freshwater strains, Synechococcus elongatus PCC 7942 (ATCC 33912) and Synechocystis sp.

373 PCC 6803 (kindly provided by Jerilyn Timlin, Sandia National Laboratories), and one marine

374 strain, Synechococcus sp. PCC 7002 (ATCC 27264). All strains used in this study are listed in 
375 Table S2 (Supplemental File). The freshwater strains were cultured in BG-11 medium, and the

376 marine strain was cultured in $\mathrm{A}+$ medium. Cultures were grown at $30^{\circ} \mathrm{C}$ in a low temperature

377 Shel Lab incubator with a VWR orbital shaker at $150 \mathrm{rpm}$ under a continuous light intensity of

378 approximately $40 \mu \mathrm{mol}$ photons $\mathrm{m}^{-2} \mathrm{~s}^{-1}$ from plant \& aquarium fluorescent lights. Cultures were

379 maintained on agar plates and inoculated into test tubes containing $4 \mathrm{~mL}$ of liquid media.

380

381

382

383

384

385

386

387

388

\subsection{Construction of Mutants}

The ROS-overexpression mutants were constructed using S. elongatus PCC 7942 with genome integration of the plasmid at neutral site II (NSII). Plasmids for genome integration and the overexpression of 4 ROS-degrading proteins (pSA_0437, pSA_0801, pSA_1214, and pSA_1656) were constructed previously [12]. The plasmids were transformed as described in [42] and screened using BG-11/agar plates supplemented with $50 \mu \mathrm{g} / \mathrm{mL}$ of kanamycin monosulfate and $1 \mathrm{mM}$ of sodium thiosulfate. Successful transformation was confirmed by PCR amplification of NSII (primers: NSII5F and NSII3R, Table A6, [12]) and PCR amplification of the 5 ' homologous region of NSII along with the target gene (primers: NSII5F and 0437R/0801R/1214R/1656R, Table A6, [12]). A control strain, 7942a, was constructed with genome integration of the empty vector, pSA [43], into NSII.

The desaturase and efflux pump knockout mutants were constructed using Synechococcus sp. PCC 7002 and the corresponding knockout plasmids. The knockout plasmids were constructed by cloning 500 bp homologous regions upstream and downstream of the 5' and 3' ends of the target gene sequence and integrating them into pSK, containing a kanamycin resistance cassette (Supplemental File, Table S5). These plasmids were linearized using SpeI digestion and transformed into Synechococcus sp. PCC 7002 as described in [42]. Transformed colonies were re-streaked a minimum of 3 times on medium $\mathrm{A}+$ agar plates containing $50 \mu \mathrm{g} / \mathrm{mL}$ 
kanamycin monosulfate and $1 \mathrm{mM}$ sodium thiosulfate to obtain homozygous strains. Gene

399 knockouts were confirmed via colony PCR of the transformants using the 5' forward and 3'

400 reverse primers in Table S5 (Supplemental File).

\subsection{Biofuel Growth Inhibition and Toxicity Studies}

402

To assess biofuel growth inhibition, the 3 cyanobacterial strains were cultivated in $16 \mathrm{x}$

$403100 \mathrm{~mm}$ test tubes with $4 \mathrm{~mL}$ of medium. When culture densities reached an $\mathrm{OD}_{730}$ of $1.0,20 \mu \mathrm{L}$

404 of culture were inoculated into a test tube containing $4 \mathrm{~mL}$ of medium with varying biofuel

405 concentrations. The short chain alcohols, absolute ethanol (Fisher) and isobutanol (2-methyl-1-

406 propanol, Fisher), were added directly to the culture medium to achieve the final biofuel

407 concentrations. The long-chain alcohol, 1-hexadecanol (Ultra Scientific), was heated in a water

408 bath at $50^{\circ} \mathrm{C}$ until melted, and the liquid 1-hexadecanol was added to the culture medium and

409 vortexed to produce a $100 \mu \mathrm{M}$ stock solution. This stock solution was further diluted with

410 medium to reach the final biofuel concentrations. For the saturated FFAs, $500 \mu \mathrm{M}$ stock

411 solutions of palmitic acid and stearic acid were made by dissolving solid sodium palmitate and

412 sodium stearate (Acros Organics) in the culture medium; these stock solutions were further

413 diluted with medium to reach the final biofuel concentrations. For the polyunsaturated FFA,

414 linolenic acid, a $200 \mu \mathrm{M}$ stock solution of $\alpha$-linolenic acid (Acros Organics) in medium was

415 prepared fresh to prevent oxidative degradation and immediately diluted to achieve the specified

416 biofuel concentrations. The long-chain alkane (n-pentadecane, Acros organics) and alkene (1-

417 heptadecene, Acros Organics) were added directly to the medium to reach the final biofuel

418 concentrations. For engineered strains containing inducible gene overexpression (7942_0437,

419 7942_0801, 7942_1214, and 7942_1656), IPTG was added at a concentration of $1 \mathrm{mM}$ prior to

420 inoculation. Cultures were grown for 5 days under constant light in slanted test tube racks as 
421 described above. On day 5, cell concentration $\left(\mathrm{OD}_{730}\right)$ and photosynthetic yield $\left(\mathrm{F}_{\mathrm{v}}{ }^{\prime} / \mathrm{F}_{\mathrm{m}}{ }^{\prime}\right)$ were

422 measured. The $\mathrm{OD}_{730}$ value for each culture was normalized using the $\mathrm{OD}_{730}$ of the control

423 culture with no biofuel addition. A minimum of three biological replicates were analyzed for

424 each biofuel concentration; data is reported as the average of these measurements with error bars

425 representing the standard deviation. For data with high standard deviation, additional biological

426 replicates were performed, up to a total of 5 replicates.

427 To determine biofuel toxicity, the 3 cyanobacterial strains were cultivated in $500 \mathrm{~mL}$

428 baffled Erlenmeyer flasks with $110 \mathrm{~mL}$ of media. When culture densities reached an $\mathrm{OD}_{730}$ of

429 1.0, the culture was aliquoted into four $125 \mathrm{~mL}$ Erlenmeyer flasks, with $25 \mathrm{~mL}$ of culture in each

430 flask. Absolute ethanol (Fisher) or $\alpha$-linolenic acid (Acros Organics) was added directly to these

431 cultures to achieve the specified biofuel concentration. The cultures were grown under the

432 conditions described previously, and each culture was sampled at $0 \mathrm{~h}$ (before the addition of

433 biofuel), $4 \mathrm{~h}, 8 \mathrm{~h}, 24 \mathrm{~h}$, and $48 \mathrm{~h}$. For each sample, the cell concentration $\left(\mathrm{OD}_{730}\right)$, photosynthetic

434 yield $\left(\mathrm{F}_{\mathrm{v}}{ }^{\prime} / \mathrm{F}_{\mathrm{m}}{ }^{\prime}\right)$, level of ROS, and cell membrane permeability were analyzed. A minimum of

435 three biological replicates were analyzed for each data point; data is reported as the average of

436 these measurements with error bars representing the standard deviation.

4374.5 Spectroscopic Measurements

$438 \quad$ Cell concentration was determined using the optical density (OD) at $730 \mathrm{~nm}$. Optical

439 densities were measured using a LambdaBio spectrophotometer from PerkinElmer. OD

440 readings were normalized to the control $\mathrm{OD}_{730}$, having no biofuel addition.

441

To measure photosynthetic yield ( $\left.\mathrm{F}_{\mathrm{v}}{ }^{\prime} / \mathrm{F}_{\mathrm{m}}{ }^{\prime}\right)$, a Waltz MINI-PAM photosynthesis yield

442 analyzer was used by pressing the probe flat against the glass surface of the culture and 
443 averaging the readings of three technical replicates for each data point. The cultures were not

444 dark-adapted prior to this measurement.

445

446

447

448

449

450

451

452

453

454

455

456

457

458

459

460

461

462

463

464

465

\subsection{Cell Membrane Permeability and ROS Measurements}

The membrane-impermeable dye, SYTOX Green Nucleic Acid Stain (Invitrogen/Life

Technologies), was used to assess cell membrane permeability upon biofuel addition in the toxicity studies. A $30 \mu \mathrm{M}$ stock solution of SYTOX was prepared using dimethyl sulfoxide (DMSO, Sigma). For SYTOX staining, $0.5 \mathrm{~mL}$ of culture was extracted from the $25 \mathrm{~mL}$ culture and placed into a $1.5 \mathrm{~mL}$ microcentrifuge tube. The SYTOX stock solution was added to the sample to obtain a final concentration of $300 \mathrm{nM}$. Samples were inverted after SYTOX addition and incubated in the dark at room temperature for $20 \mathrm{~min}$. Samples were then diluted $20-100 \mathrm{x}$ before running on an Accuri C6 flow cytometer. The flow cytometer was used to analyze the cell population, using a 20,000 event limit, slow fluidics speed, and threshold of 40,000 for FSC-H. Cells with increased fluorescence emission at $533 \mathrm{~nm}$ were determined to have positive SYTOX staining, indicating enhanced cell membrane permeability.

The ROS-reactive dye, 2,7-dichloro fluorescein diacetate ( $\mathrm{H}_{2}$ DCFDA, Sigma-Aldrich), was used to assess intracellular ROS levels. A stock solution of $10.2 \mathrm{mM} \mathrm{H}_{2}$ DCFDA was prepared using DMSO. For ROS staining, $0.5 \mathrm{~mL}$ of culture was extracted and placed into a 1.5 mL microcentrifuge tube. The $\mathrm{H}_{2}$ DCFDA stock solution was added to the sample to achieve a final concentration of $102 \mu \mathrm{M}$. DMSO $(20 \mu \mathrm{L})$ was also added to permeabilize the cells and allow for $\mathrm{H}_{2}$ DCFDA uptake. Samples were inverted after $\mathrm{H}_{2}$ DCFDA addition and incubated under growth conditions for $1 \mathrm{~h}$. Samples were then diluted $20-100 x$ and analyzed using flow cytometry with the aforementioned settings. Cells with increased fluorescence emission at 533 nm were determined to be positive for elevated ROS levels. 

row.

Each of the 3 model cyanobacterial strains was cultivated in a $500 \mathrm{~mL}$ baffled Erlenmeyer flask with $100 \mathrm{~mL}$ of medium. After 5 days of continuous cultivation, $50 \mathrm{~mL}$ of culture was used for lipid extraction. Cellular lipids were extracted using a chloroform-methanol extraction [9] and dried under a stream of nitrogen. The dried samples were solubilized and analyzed using electrospray ionization - mass spectrometry (ESI-MS) at the Kansas Lipidomics Research Center. For each strain, three biological replicates were analyzed, and the data is an average of these replicates \pm the standard deviation of these measurements.

\subsection{Comparative Genomics}

The genome sequences of the 3 cyanbacterial species, S. elongatus PCC 7942, Synechococcus sp. PCC 7002, and Synechocystis sp. PCC 6803, were analyzed to identify genes associated with 3 potential mechanisms of biofuel tolerance: 1) the degree of membrane saturation, 2) ROS-degrading proteins, and 3) efflux pump proteins. The genomes were mined manually for predicted genes with functional annotations related to these potential mechanisms. As the level of functional annotation may differ among these three genomes, a comparative genome analysis was performed using the Microbial Genome Database (MBGD) for Comparative Analysis [44] to identify homologs among the three cyanobacterial species. The results of these analyses are summarized in Table 2, with homologous genes listed in the same

\section{Abbreviations}

2-AL

2-acetolactate

2,3-dihydroxy-isovalerate

2-ketoisovalerate 


\begin{tabular}{|c|c|c|}
\hline 489 & 2-OG & 2-oxoglutarate \\
\hline 490 & 3-PGA & 3-phosphoglycerate \\
\hline 491 & AA & acetaldehyde \\
\hline 492 & $\mathrm{ACP}$ & acyl carrier protein \\
\hline 493 & acyl-A & acyl-aldehyde \\
\hline 494 & CL & cardiolipin \\
\hline 495 & $\mathrm{CoA}$ & Coenzyme A \\
\hline 496 & DMSO & dimethyl sulfoxide \\
\hline 497 & ESI-MS & electrospray ionization - mass spectrometry \\
\hline 498 & $\mathrm{EtOH}$ & ethanol \\
\hline 499 & F6P & fructose-6-phosphate \\
\hline 500 & FA & fatty acid \\
\hline 501 & FFA & free fatty acid \\
\hline 502 & Glc & glucose \\
\hline 503 & $\mathrm{H}_{2}$ DCFDA & 2,7-dichloro fluorescein diacetate \\
\hline 504 & IBA & isobutyraldehyde \\
\hline 505 & IBOH & isobutanol \\
\hline 506 & IPTG & isopropyl $\beta$-D-1-thiogalactopyranoside \\
\hline 507 & LA & $\alpha$-linolenic acid \\
\hline 508 & LPS & lipopolysaccharides \\
\hline 509 & MBGD & microbial genome database \\
\hline 510 & OAA & oxaloacetate \\
\hline 511 & OD & optical density \\
\hline
\end{tabular}




$\begin{array}{lll}512 & \mathrm{P}_{\text {ow }} & \text { partition coefficient in n-octanol and water } \\ 513 & \text { PE } & \text { phosphatidylethanolamine } \\ 514 & \text { PEP } & \text { phosphoenolpyruvate } \\ 515 & \text { PG } & \text { phosphatidylglycerol } \\ 516 & \text { PPP } & \text { pentose phosphate pathway } \\ 517 & \text { PYR } & \text { pyruvate } \\ 518 & \text { ROS } & \text { reactive oxygen species } \\ 519 & \text { RuBP } & \text { ribulose-1,5-bisphosphate } \\ 520 & \text { TCA } & \text { tricarboxylic acid } \\ 521 & \text { Val } & \text { valine }\end{array}$

522 6. Acknowledgements

523 This work was supported by the Harry S. Truman Fellowship in National Security Science and 524 Engineering and an Early Career Award, both funded by the Laboratory Directed Research and 525 Development program at Sandia National Laboratories. Sandia is a multi-program laboratory 526 operated by Sandia Corporation, a Lockheed Martin Company, for the United States Department 527 of Energy under Contract DE-ACO4-94AL85000. The author also acknowledges Dr. Jerilyn 528 Timlin (SNL) for providing Synechocystis sp. PCC 6803 and Dr. Bryan Carson (SNL) for his 529 generosity in sharing equipment. Lipid analysis was performed by Drs. Mary Roth and Ruth 530 Welti at the Kansas Lipidomics Research Center. Instrument acquisition and method 531 development at the Kansas Lipidomics Research Center was supported by NSF grants MCB 5320455318 and DBI 0521587, K-INBRE (NIH Grant P20 RR16475 from the INBRE program of 533 the National Center for Research Resources), and NSF EPSCoR grant EPS-0236913 with 
matching support from the State of Kansas through Kansas Technology Enterprise Corporation and Kansas State University.

\section{References}

1. Deng, M.-D. and J.R. Coleman, Ethanol Synthesis by Genetic Engineering in Cyanobacteria. Applied and Environmental Microbiology, 1999. 65(2): p. 523-528.

2. Dexter, J. and P. Fu, Metabolic Engineering of Cyanobacteria for Ethanol Production. Energy \& Environmental Science, 2009. 2(8): p. 857-864. DOI: 10.1039/B811937F.

3. Atsumi, S., W. Higashide, and J.C. Liao, Direct Photosynthetic Recycling of Carbon Dioxide to Isobutyraldehyde. Nat Biotech, 2009. 27(12): p. 1177-1180. DOI: 10.1038/nbt.1586.

4. Lan, E.I. and J.C. Liao, Metabolic Engineering of Cyanobacteria for 1-Butanol Production from Carbon Dioxide. Metabolic Engineering, 2011. 13(4): p. 353-363. DOI: http://dx.doi.org/10.1016/j.ymben.2011.04.004.

5. Bentley, F.K., A. Zurbriggen, and A. Melis, Heterologous Expression of the Mevalonic Acid Pathway in Cyanobacteria Enhances Endogenous Carbon Partitioning to Isoprene. Molecular Plant, 2013. DOI: 10.1093/mp/sst134.

6. Lindberg, P., S. Park, and A. Melis, Engineering a Platform for Photosynthetic Isoprene Production in Cyanobacteria, Using Synechocystis as the Model Organism. Metabolic Engineering, 2010. 12(1): p. 70-79. DOI: 10.1016/j.ymben.2009.10.001.

7. Englund, E., et al., Production of Squalene in Synechocystis Sp. Pcc 6803. PLoS ONE, 2014. 9(3): p. e90270. DOI: 10.1371/journal.pone.0090270.

8. Liu, X., J. Sheng, and R. Curtiss III, Fatty Acid Production in Genetically Modified Cyanobacteria. Proceedings of the National Academy of Sciences, 2011. 108(17): p. 6899-6904. DOI: 10.1073/pnas.1103014108.

9. $\quad$ Ruffing, A.M. and H.D.T. Jones, Physiological Effects of Free Fatty Acid Production in Genetically Engineered Synechococcus Elongatus Pcc 7942. Biotechnology and Bioengineering, 2012. 109(9): p. 2190-2199. DOI: 10.1002/bit.24509.

10. Tan, X., et al., Photosynthesis Driven Conversion of Carbon Dioxide to Fatty Alcohols and Hydrocarbons in Cyanobacteria. Metabolic Engineering, 2011. 13(2): p. 169-176.

11. Wang, W., X. Liu, and X. Lu, Engineering Cyanobacteria to Improve Photosynthetic Production of Alka(E)Nes. Biotechnology for Biofuels, 2013. 6(69).

12. Ruffing, A.M., Rna-Seq Analysis and Targeted Mutagenesis for Improved Free Fatty Acid Production in an Engineered Cyanobacterium. Biotechnology for Biofuels, 2013. 6(13).

13. Liu, J., et al., Proteomic Analysis Reveals Resistance Mechanism against Biofuel Hexane in Synechocystis Sp. Pcc 6803. Biotechnol Biofuels, 2012. 5(1): p. 68.

14. Qiao, J., et al., Quantitative Itraq Lc-Ms/Ms Proteomics Reveals Metabolic Responses to Biofuel Ethanol in Cyanobacterial Synechocystis Sp. Pcc 6803. Journal of Proteome Research, 2012. 11(11): p. 5286-5300. DOI: 10.1021/pr300504w. 
15. Tian, X., et al., Quantitative Proteomics Reveals Dynamic Responses of Synechocystis Sp. Pcc 6803 to Next-Generation Biofuel Butanol. Journal of Proteomics, 2013. 78(0): p. 326-345. DOI: http://dx.doi.org/10.1016/j.jprot.2012.10.002.

16. Wang, J., et al., Rna-Seq Based Identification and Mutant Validation of Gene Targets Related to Ethanol Resistance in Cyanobacterial Synechocystis Sp. Pcc 6803. Biotechnology for Biofuels, 2012. 5(1): p. 89.

17. Zhu, H., et al., Integrated Omics Guided Engineering of Biofuel Butanol-Tolerance in Photosynthetic Synechocystis Sp. Pcc 6803. Biotechnology for Biofuels, 2013. 6(1): p. 106.

18. Ingram, L.O., Ethanol Tolerance in Bacteria. Critical Reviews in Biotechnology, 1989. 9(4): p. 305-319. DOI: 10.3109/07388558909036741.

19. Ma, M. and Z.L. Liu, Mechanisms of Ethanol Tolerance in Saccharomyces Cerevisiae. Applied Microbiology and Biotechnology, 2010. 87(3): p. 829-845. DOI: 10.1007/s00253-010-2594-3.

20. León, R., et al., Organic Solvent Toxicity in Photoautotrophic Unicellular Microorganisms. Enzyme and Microbial Technology, 2001. 29(2-3): p. 173-180.

21. Stratton, G., Toxic Effects of Organic Solvents on the Growth of Blue-Green Algae. Bulletin of Environmental Contamination and Toxicology, 1987. 38(6): p. 1012-1019. DOI: $10.1007 / \mathrm{bf01609089.}$

22. Kämäräinen, J., et al., Physiological Tolerance and Stoichiometric Potential of Cyanobacteria for Hydrocarbon Fuel Production. Journal of Biotechnology, 2012. 162(1): p. 67-74. DOI: http://dx.doi.org/10.1016/j.jbiotec.2012.07.193.

23. Ramos, J.L., et al., Mechanisms of Solvent Tolerance in Gram-Negative Bacteria. Annual Review of Microbiology, 2002. 56(1): p. 743-768. DOI: 10.1146/annurev.micro.56.012302.161038.

24. Sikkema, J., J.A. de Bont, and B. Poolman, Mechanisms of Membrane Toxicity of Hydrocarbons. Microbiological Reviews, 1995. 59(2): p. 201-22.

25. Desbois, A. and V. Smith, Antibacterial Free Fatty Acids: Activities, Mechanisms of Action and Biotechnological Potential. Applied Microbiology and Biotechnology, 2010. 85(6): p. 1629-1642. DOI: 10.1007/s00253-009-2355-3.

26. Heipieper, H.J., et al., Mechanisms of Resistance of Whole Cells to Toxic Organic Solvents. Trends in Biotechnology, 1994. 12(10): p. 409-415. DOI: http://dx.doi.org/10.1016/0167-7799(94)90029-9.

27. Dunlop, M.J., Engineering Microbes for Tolerance to Next-Generation Biofuels. Biotechnology for Biofuels, 2011. 4(32).

28. Dunlop, M.J., et al., Engineering Microbial Biofuel Tolerance and Export Using Efflux Pumps. Mol Syst Biol, 2011. 7. DOI: http://www.nature.com/msb/journal/v7/n1/suppinfo/msb201121-dfs3_S1.html.

29. Sardessai, Y. and S. Bhosle, Tolerance of Bacteria to Organic Solvents. Research in Microbiology, 2002. 153(5): p. 263-268.

30. Nicolaou, S.A., S.M. Gaida, and E.T. Papoutsakis, A Comparative View of Metabolite and Substrate Stress and Tolerance in Microbial Bioprocessing: From Biofuels and Chemicals, to Biocatalysis and Bioremediation. Metabolic Engineering, 2010. 12(4): p. 307-331. DOI: http://dx.doi.org/10.1016/j.ymben.2010.03.004. 
651

652

653

654

655

656

657

658

659

660

661

662

31. Ludwig, M. and D.A. Bryant, Synechococcus Sp. Strain Pcc 7002 Transcriptome: Acclimation to Temperature, Salinity, Oxidative Stress and Mixotrophic Growth Conditions. Frontiers in Microbiology, 2012. 3. DOI: 10.3389/fmicb.2012.00354.

32. Nomura, C., T. Sakamoto, and D. Bryant, Roles for Heme-Copper Oxidases in Extreme High-Light and Oxidative Stress Response in the Cyanobacterium Synechococcus Sp. Pcc 7002. Archives of Microbiology, 2006. 185(6): p. 471-479. DOI: 10.1007/s00203-0060107-7.

33. Singh, S.C., R.P. Sinha, and D.P. Hader, Role of Lipids and Fatty Acids in Stress Tolerance in Cyanobacteria. Acta protozoologica, 2002. 41(4): p. 297-308.

34. Knoshaug, E. and M. Zhang, Butanol Tolerance in a Selection of Microorganisms. Applied Biochemistry and Biotechnology, 2009. 153(1-3): p. 13-20. DOI: 10.1007/s12010-008-8460-4.

35. Campbell, D., et al., Chlorophyll Fluorescence Analysis of Cyanobacterial Photosynthesis and Acclimation. Microbiology and Molecular Biology Reviews, 1998. 62(3): p. 667-683.

36. Rodríguez-Vargas, S., et al., Fluidization of Membrane Lipids Enhances the Tolerance of Saccharomyces Cerevisiae to Freezing and Salt Stress. Applied and Environmental Microbiology, 2007. 73(1): p. 110-116. DOI: 10.1128/aem.01360-06.

37. Sakamoto, T., et al., Low-Temperature-Induced Desaturation of Fatty Acids and Expression of Desaturase Genes in the Cyanobacterium Synechococcus Sp. Pcc 7002. FEMS Microbiology Letters, 1997. 152(2): p. 313-320. DOI: 10.1111/j.15746968.1997.tb10445.x.

38. Apel, K. and H. Hirt, Reactive Oxygen Species: Metabolism, Oxidative Stress, and Signal Transduction. Annual Review of Plant Biology, 2004. 55(1): p. 373-399. DOI: doi:10.1146/annurev.arplant.55.031903.141701.

39. Kaczmarzyk, D., et al., Overexpression of Sigma Factor Sigb Improves Temperature and Butanol Tolerance of Synechocystis Sp. Pcc6803. Journal of Biotechnology, 2014. 182183(0): p. 54-60. DOI: http://dx.doi.org/10.1016/j.jbiotec.2014.04.017.

40. Lennen, R.M., et al., Identification of Transport Proteins Involved in Free Fatty Acid Efflux in Escherichia Coli. Journal of Bacteriology, 2013. 195(1): p. 135-144. DOI: 10.1128/jb.01477-12.

41. Lennen, R.M., et al., Membrane Stresses Induced by Overproduction of Free Fatty Acids in Escherichia Coli. Applied and Environmental Microbiology, 2011. 77(22): p. 81148128. DOI: 10.1128/aem.05421-11.

42. Ruffing, A., Improved Free Fatty Acid Production in Cyanobacteria with Synechococcus Sp. Pcc 7002 as Host. Frontiers in Bioengineering \& Biotechnology, 2014. Submitted.

43. Ruffing, A.M., Borrowing Genes from Chlamydomonas Reinhardtii for Free Fatty Acid Production in Engineered Cyanobacteria. Journal of Applied Phycology, 2013. 25(5): p. 1495-1507.

44. Uchiyama, I., et al., Mbgd Update 2013: The Microbial Genome Database for Exploring the Diversity of Microbial World. Nucleic Acids Research, 2013. 41(D1): p. D631-D635. DOI: $10.1093 / \mathrm{nar} / \mathrm{gks} 1006$. 
663

664

665

666

667

668

669

670

671

672

673

674

675

676

677

678

679

680

681

682

683

684

685

686

\section{Figure Captions}

Figure 1. Simplified schematic of cyanobacterial metabolism. Potential biofuel targets are highlighted by dashed boxes; dashed arrows indicate non-native enzymatic steps. Abbreviations 2-AL: 2-acetolactate; 2,3-DHIV: 2,3-dihydroxy-isovalerate; 2-KIV: 2-ketoisovalerate; 2-OG: 2oxoglutarate; 3-PGA: 3-phosphoglycerate; AA: acetaldehyde; ACP: acyl carrier protein; acyl-A: acyl-aldehyde; CoA: Coenzyme A; EtOH: ethanol; F6P: fructose-6-phosphate; FFA: free fatty acid; Glc: glucose; IBA: isobutyraldehyde; IBOH: isobutanol; OAA: oxaloacetate; PEP: phosphoenolpyruvate; PPP: pentose phosphate pathway; PYR: pyruvate; RuBP: ribulose-1,5bisphosphate; TCA: tricarboxylic acid; Val: valine.

Figure 2. Relative growth inhibition of three model cyanobacteria exposed to various concentrations of biofuel products. Optical densities are normalized to an $\mathrm{OD}_{730}=1.0$ for the control cultures, with no biofuel addition. Data are an average of at least 3 biological replicates; measurements with high variation between replicates were independently repeated up to 5 times. Error bars represent the standard deviation of biological replicates. Abbreviations - 7942: $S$. elongatus PCC 7942; 6803: Synechocystis sp. PCC 6803; 7002: Synechococcus sp. PCC 7002.

Figure 3. Photosynthetic yields $\left(\mathrm{F}_{\mathrm{v}}{ }^{\prime} / \mathrm{F}_{\mathrm{m}}\right.$ ') of three model cyanobacteria exposed to various concentrations of biofuel products. Each measurement is the average of 3 technical replicate measurements, and data are an average of at least 3 biological replicates. Error bars represent the standard deviation of the biological replicates, as this was more significant than the technical replicate variation. Abbreviations - 7942: S. elongatus PCC 7942; 6803: Synechocystis sp. PCC 6803; 7002: Synechococcus sp. PCC 7002. 
688 Figure 4. Physiological effects of ethanol toxicity in cyanobacterial cultures during the 689 exponential growth phase. Physiological measurements include normalized growth (A, D, and $690 \mathrm{G})$, photosynthetic yields $\left(\mathrm{F}_{\mathrm{v}}{ }^{\prime} / \mathrm{F}_{\mathrm{m}}{ }^{\prime}\right)(\mathrm{B}, \mathrm{E}$, and $\mathrm{H})$, and percentage of membrane-permeable cells 691 (C, F, and I) for cultures of S. elongatus PCC 7942 (A, B, and C), Synechocystis sp. PCC 6803 692 (D, E, and F), and Synechococcus sp. PCC 7002 (G, H, and I). Note: Ethanol concentrations are 693 higher for Synechococcus sp. PCC 7002 cultures (G, H, and I) due to its higher ethanol tolerance. 694 Data are an average of at least 3 biological replicates with error bars representing the standard 695 deviation.

697 Figure 5. Relative growth inhibition of genetically modified cyanobacteria exposed to various 698 concentrations of ethanol. Optical densities are normalized to an $\mathrm{OD}_{730}=1.0$ for the control 699 cultures, with no biofuel addition. Cyanobacterial mutants include desaturase knockout mutants 700 of Synechococcus sp. PCC 7002 (A), ROS-degrading protein overexpression mutants of $S$. 701 elongatus PCC 7942 (B), and efflux pump mutants of Synechococcus sp. PCC 7002 (C). Data are 702 an average of at least 3 biological replicates with error bars representing the standard deviation. 


\section{Acknowledgements}

This work was supported by the Harry S. Truman Fellowship in National Security Science and Engineering and an Early Career Award, both funded by the Laboratory Directed Research and Development program at Sandia National Laboratories. Sandia is a multi-program laboratory operated by Sandia Corporation, a Lockheed Martin Company, for the United States Department of Energy under Contract DE-ACO4-94AL85000. The author also acknowledges Dr. Jerilyn Timlin (SNL) for providing Synechocystis sp. PCC 6803 and Dr. Bryan Carson (SNL) for his generosity in sharing equipment. Lipid analysis was performed by Drs. Mary Roth and Ruth Welti at the Kansas Lipidomics Research Center. Instrument acquisition and method development at the Kansas Lipidomics Research Center was supported by NSF grants MCB 0455318 and DBI 0521587, K-INBRE (NIH Grant P20 RR16475 from the INBRE program of the National Center for Research Resources), and NSF EPSCoR grant EPS-0236913 with matching support from the State of Kansas through Kansas Technology Enterprise Corporation and Kansas State University. 
Table 1. Degree of saturation of fatty acids in lipids of 3 model cyanobacteria: S. elongatus PCC 7942, Synechocystis sp. PCC 6803, and Synechococcus sp. PCC 7002. Composition determined using ESI-MS. Data are averages of 3 biological replicates, reported with the standard deviation.

\begin{tabular}{|l|l|l|l|l|l|l|l|}
\hline \multirow{2}{*}{ Strain } & \multicolumn{7}{|c|}{ Number of Double Bonds in Lipid Molecules (\% of total signal) } \\
\cline { 2 - 8 } & \multicolumn{1}{|c}{$\mathbf{0}$} & $\mathbf{1}$ & $\mathbf{2}$ & $\mathbf{3}$ & $\mathbf{4}$ & $\mathbf{5}$ & $\mathbf{6}$ \\
\hline 7942 & $2.07 \pm 0.185$ & $74.3 \pm 3.65$ & $15.1 \pm 1.26$ & $5.49 \pm 9.15$ & $2.87 \pm 0.792$ & $0.054 \pm 0.034$ & $0.128 \pm 0.016$ \\
\hline 6803 & $1.48 \pm 0.234$ & $9.83 \pm 0.913$ & $15.7 \pm 1.79$ & $63.1 \pm 5.16$ & $7.92 \pm 0.914$ & $1.45 \pm 0.123$ & $0.534 \pm 0.323$ \\
\hline 7002 & $0.945 \pm 0.327$ & $21.2 \pm 2.79$ & $27.3 \pm 1.63$ & $39.7 \pm 8.89$ & $9.63 \pm 0.623$ & $1.11 \pm 0.924$ & $0.060 \pm 0.039$ \\
\hline
\end{tabular}


Table 2. Comparative genomics for 3 model cyanobacterial strains. Genes which may contribute to cyanobacterial biofuel tolerance are analyzed, including desaturases, ROS-degrading proteins, and efflux pump proteins. Homologous genes are listed in each row.

\begin{tabular}{|c|c|c|c|c|c|}
\hline \multicolumn{2}{|c|}{ Synechococcus elongatus PCC 7942} & \multicolumn{2}{|c|}{ Synechocystis sp. PCC 6803} & \multicolumn{2}{|c|}{ Synechococcus sp. PCC 7002} \\
\hline Locus Tag & \begin{tabular}{|l|} 
Description \\
\end{tabular} & Locus Tag & Description & Locus Tag & Description \\
\hline \multicolumn{6}{|l|}{ Desaturases } \\
\hline \multirow[t]{6}{*}{ Synpcc7942_2561 } & $\begin{array}{l}\text { delta-9 acyl- } \\
\text { phospholipid desaturase }\end{array}$ & sl10541 & $\begin{array}{l}\text { acyl-CoA } \\
\text { desaturase (DesC) }\end{array}$ & SYNPCC7002_A2198 & $\begin{array}{l}\text { delta-9 acyl-lipid } \\
\text { desaturase (DesC) }\end{array}$ \\
\hline & & slr1350 & $\begin{array}{l}\text { fatty acid } \\
\text { desaturase, } \\
\text { homology to } \\
\text { sll1441 (DesA) }\end{array}$ & SYNPCC7002_A2756 & $\begin{array}{l}\text { homology to } \\
\text { SYNPCC70025_A0159 } \\
\text { (DesA) }\end{array}$ \\
\hline & & sll1441 & $\begin{array}{l}\text { delta } 15 \text { desaturase, } \\
\text { homology to } \\
\text { slr1350 (DesB) }\end{array}$ & SYNPCC7002_A0159 & $\begin{array}{l}\text { omega-3 acyl-lipid } \\
\text { desaturase, homology to } \\
\text { SYNPCC7002_A2756 } \\
\text { (DesB) }\end{array}$ \\
\hline & & sl10262 & $\begin{array}{l}\text { delta-6 desaturase } \\
\text { (DesD) }\end{array}$ & & \\
\hline & & & & SYNPCC7002_A1989 & $\begin{array}{l}\text { syn-2, delta } 9 \text { acyl-lipid } \\
\text { fatty acid desaturase } \\
\text { (DesF) }\end{array}$ \\
\hline & & & & SYNPCC7002_A2833 & $\begin{array}{l}\text { fatty acid desaturase } \\
\text { (DesE) }\end{array}$ \\
\hline \multicolumn{6}{|c|}{ ROS-Degrading Proteins } \\
\hline Synpcc7942_0801 & superoxide dismutase & $\operatorname{slr} 1516$ & $\begin{array}{l}\text { superoxide } \\
\text { dismutase (SodB) }\end{array}$ & SYNPCC7002_A0242 & $\begin{array}{l}\text { Mn-superoxide } \\
\text { dismutase (SodB) }\end{array}$ \\
\hline Synpcc7942_1214 & glutathione peroxidase & slr1171 & $\begin{array}{l}\text { glutathione } \\
\text { peroxidase }\end{array}$ & SYNPCC7002_A0117 & $\begin{array}{l}\text { glutathione peroxidase } \\
\text { (Gpo) }\end{array}$ \\
\hline Synpcc7942_1656 & catalase/peroxidase HPI & sl11987 & $\begin{array}{l}\text { catalase HPI } \\
(\mathrm{KatG})\end{array}$ & SYNPCC7002_A2422 & $\begin{array}{l}\text { catalase/peroxidase HPI } \\
\text { (KatG) }\end{array}$ \\
\hline Synpcc7942_1937 & $\begin{array}{l}\text { peptide methionine } \\
\text { sulfoxide reductase }\end{array}$ & s111394 & $\begin{array}{l}\text { methionine } \\
\text { sulfoxide reductase } \\
\text { A (MsrA) }\end{array}$ & SYNPCC7002_A0215 & $\begin{array}{l}\text { methionine sulfoxide } \\
\text { reductase A (MsrA) }\end{array}$ \\
\hline Synpcc7942_2190 & methionine sulfoxide & sl11680 & methionine & SYNPCC7002_A0672 & methionine-R-sulfoxide \\
\hline
\end{tabular}




\begin{tabular}{|c|c|c|c|c|c|}
\hline & reductase B & & $\begin{array}{l}\text { sulfoxide reductase } \\
\mathrm{B}(\mathrm{MsrB})\end{array}$ & & reductase $(\mathrm{MsrB})$ \\
\hline Synpcc7942_0437 & glutathione peroxidase & & & & \\
\hline \multirow[t]{3}{*}{ Synpcc7942_B2620 } & putative catalase & & & & \\
\hline & & slr1992 & $\begin{array}{l}\text { glutathione } \\
\text { peroxidase }\end{array}$ & SYNPCC7002_A0970 & glutathione peroxidase \\
\hline & & slr1795 & $\begin{array}{l}\text { methionine } \\
\text { sulfoxide reductase } \\
\text { A (MsrA) }\end{array}$ & & \\
\hline \multicolumn{6}{|l|}{ Efflux Pump Proteins } \\
\hline Synpcc7942_1869 & $\begin{array}{l}\text { cation efflux system } \\
\text { protein }\end{array}$ & sll0142 & $\begin{array}{l}\text { cation or drug } \\
\text { efflux system } \\
\text { protein }\end{array}$ & SYNPCC7002_A0587 & $\begin{array}{l}\text { cation efflux system } \\
\text { protein }(\mathrm{CzcA})\end{array}$ \\
\hline Synpcc7942_1938 & $\begin{array}{l}\text { multidrug-efflux } \\
\text { transporter }\end{array}$ & slr0944 & $\begin{array}{l}\text { hypothetical } \\
\text { protein }\end{array}$ & SYNPCC7002_A0589 & $\begin{array}{l}\text { arsenite efflux pump } \\
\text { ACR3 }\end{array}$ \\
\hline Synpcc7942_2032 & $\begin{array}{l}\text { multidrug-efflux } \\
\text { transporter quinolene } \\
\text { resistance protein } \\
\text { (NorA) }\end{array}$ & sll1154 & $\begin{array}{l}\text { quinolene } \\
\text { resistance protein } \\
\text { (NorA) }\end{array}$ & SYNPCC7002_A0087 & $\begin{array}{l}\text { major facilitator } \\
\text { transporter }\end{array}$ \\
\hline Synpcc7942_2369 & $\begin{array}{l}\text { hydrophobe/amphiphile } \\
\text { efflux-1 HAE1 }\end{array}$ & slr2131 & $\begin{array}{l}\text { cation or drug } \\
\text { efflux system } \\
\text { protein }\end{array}$ & SYNPCC7002_A1013 & $\begin{array}{l}\text { hydrophobe/amphiphile } \\
\text { efflux-1 (HAE1) family } \\
\text { protein }\end{array}$ \\
\hline Synpcc7942_2368 & secretion protein (HlyD) & sl10180 & $\begin{array}{l}\text { hypothetical } \\
\text { protein }\end{array}$ & SYNPCC7002_A1574 & $\begin{array}{l}\text { RND family efflux } \\
\text { transporter MFP subunit }\end{array}$ \\
\hline Synpcc7942_1989 & $\begin{array}{l}\text { cation diffusion } \\
\text { facilitator family } \\
\text { transporter }\end{array}$ & sl11263 & $\begin{array}{l}\text { hypothetical } \\
\text { protein }\end{array}$ & SYNPCC7002_A2463 & $\begin{array}{l}\text { cation efflux system } \\
\text { protein }\end{array}$ \\
\hline Synpcc7942_0553 & secretion protein (HlyD) & slr1207 & $\begin{array}{l}\text { hypothetical } \\
\text { protein }\end{array}$ & SYNPCC7002_A2552 & $\begin{array}{l}\text { RND family efflux } \\
\text { transporter MFP subunit }\end{array}$ \\
\hline Synpcc7942_1761 & hypothetical protein & $\operatorname{slr} 1270$ & $\begin{array}{l}\text { hypothetical } \\
\text { protein }\end{array}$ & SYNPCC7002_A0585 & $\begin{array}{l}\text { Outer membrane efflux } \\
\text { protein }\end{array}$ \\
\hline Synpcc7942_1870 & secretion protein (HlyD) & sll0141 & $\begin{array}{l}\text { hypothetical } \\
\text { protein }\end{array}$ & SYNPCC7002_A0591 & $\begin{array}{l}\text { RND family efflux } \\
\text { transporter MFP subunit }\end{array}$ \\
\hline
\end{tabular}




\begin{tabular}{|c|c|c|c|c|c|}
\hline Synpcc7942_0985 & hypothetical protein & slr1935 & $\begin{array}{l}\text { hypothetical } \\
\text { protein }\end{array}$ & SYNPCC7002_A0719 & $\begin{array}{l}\text { multidrug efflux } \\
\text { transporter }\end{array}$ \\
\hline Synpcc7942_1699 & $\begin{array}{l}\text { MATE efflux family } \\
\text { protein }\end{array}$ & slr0896 & $\begin{array}{l}\text { Probable multidrug } \\
\text { resistance protein } \\
\text { (NorM) }\end{array}$ & & \\
\hline \multirow[t]{7}{*}{ Synpcc7942_0792 } & $\begin{array}{l}\text { multidrug efflux MFS } \\
\text { transporter }\end{array}$ & & & & \\
\hline & & slr0369 & $\begin{array}{l}\text { cation or drug } \\
\text { efflux system } \\
\text { protein }\end{array}$ & & \\
\hline & & slr0794 & $\begin{array}{l}\text { cation or drug } \\
\text { efflux system } \\
\text { protein }\end{array}$ & & \\
\hline & & slr0454 & $\begin{array}{l}\text { cation or drug } \\
\text { efflux system } \\
\text { protein }\end{array}$ & & \\
\hline & & & & SYNPCC7002_A1483 & $\begin{array}{l}\text { RND family efflux } \\
\text { transporter MFP subunit }\end{array}$ \\
\hline & & & & SYNPCC7002_A1723 & $\begin{array}{l}\text { HlyD family secretion } \\
\text { protein, homology to } \\
\text { SYNPCC7002_A1483 }\end{array}$ \\
\hline & & & & SYNPCC7002_A2628 & $\begin{array}{l}\text { AcrB/AcrD/AcrF } \\
\text { family protein }\end{array}$ \\
\hline
\end{tabular}




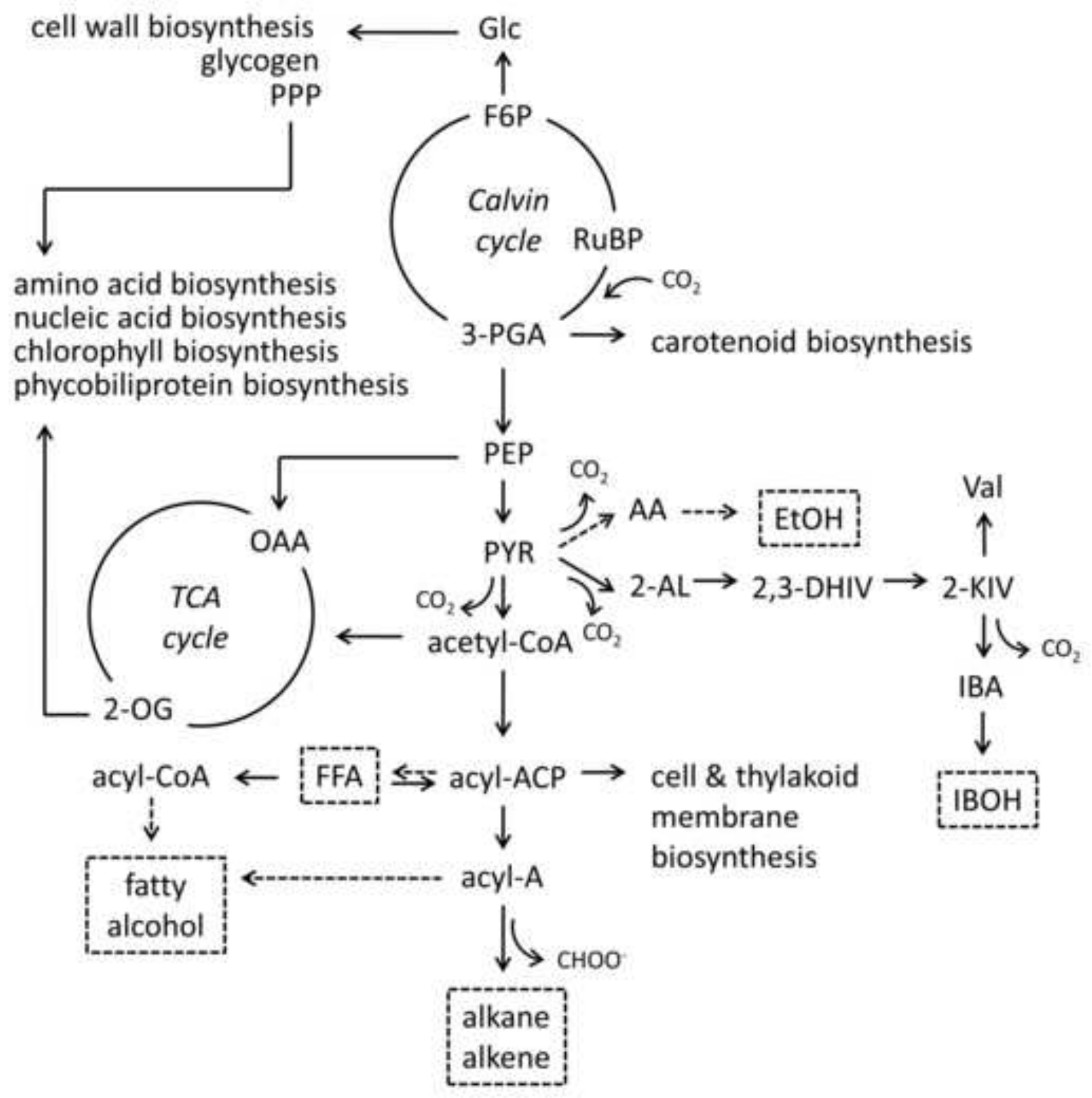


Figure 2
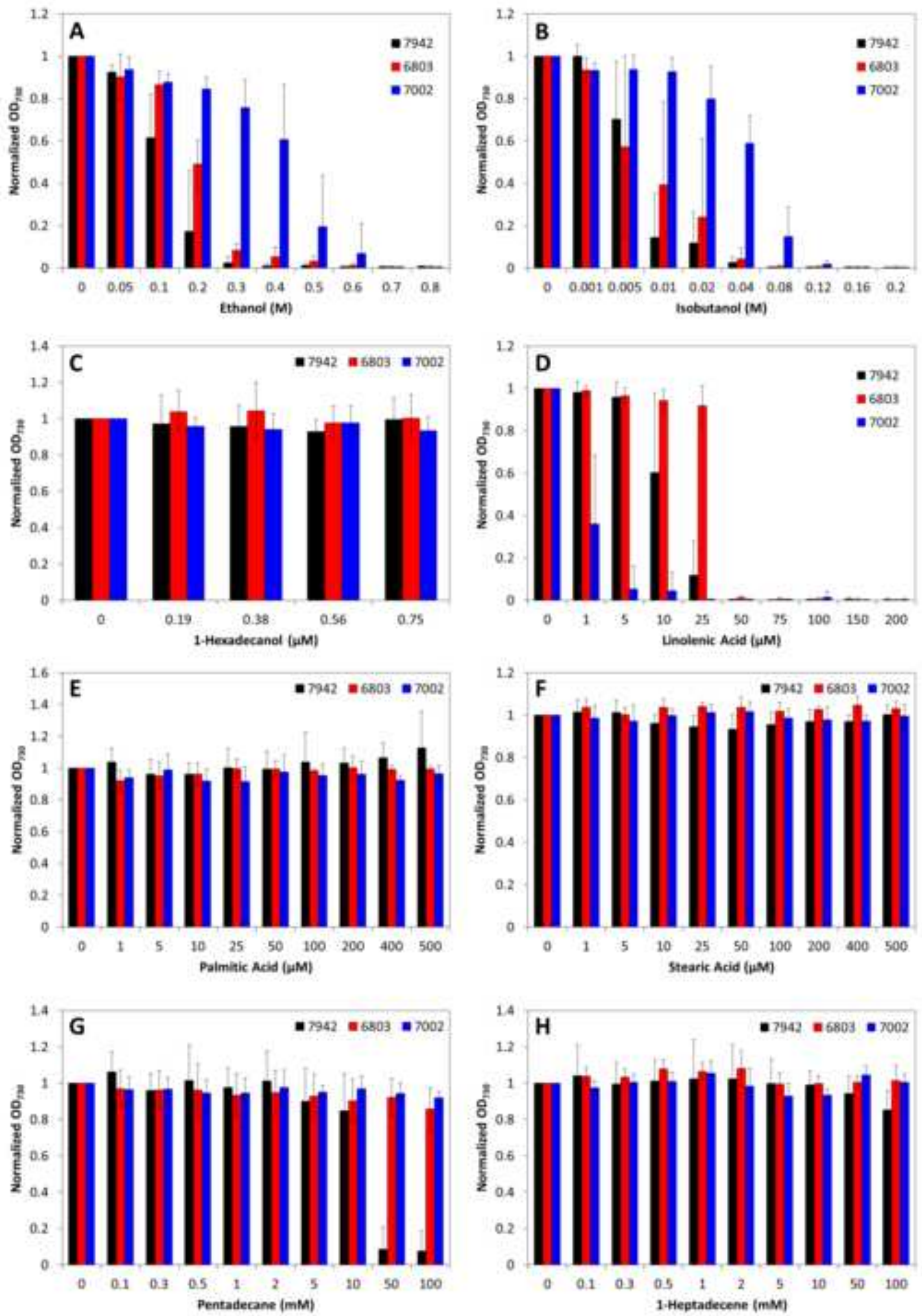
Figure 3
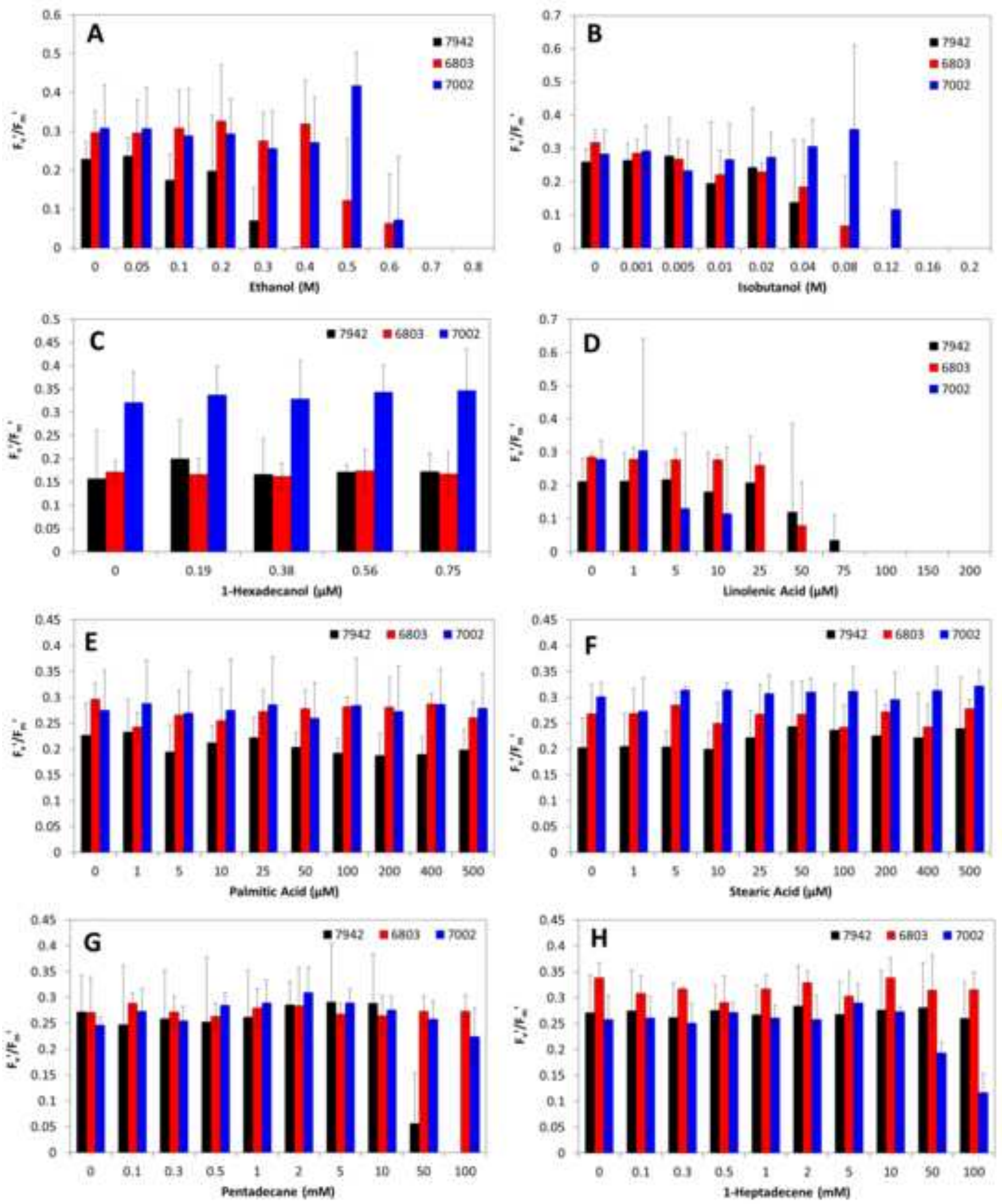

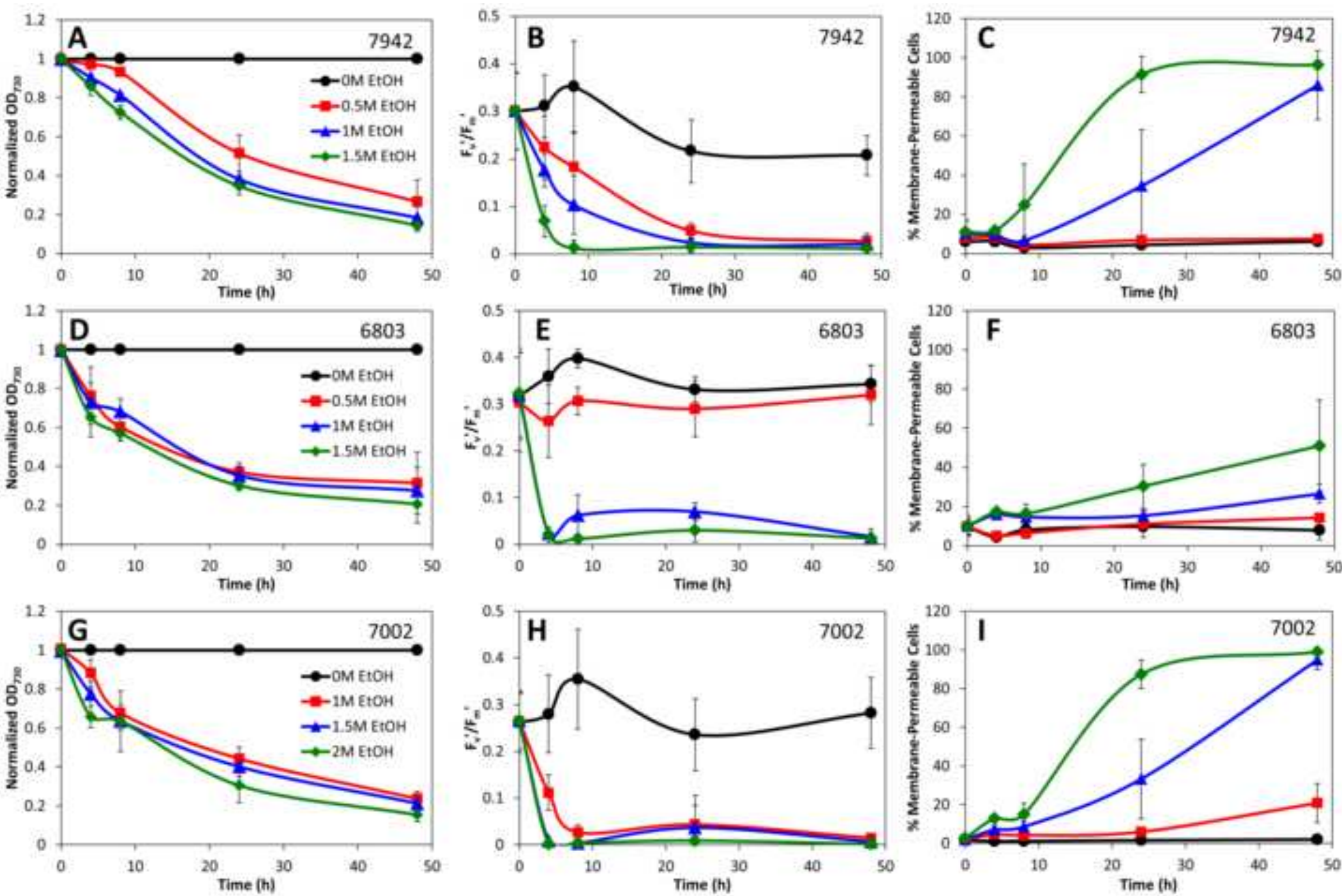
Figure 5
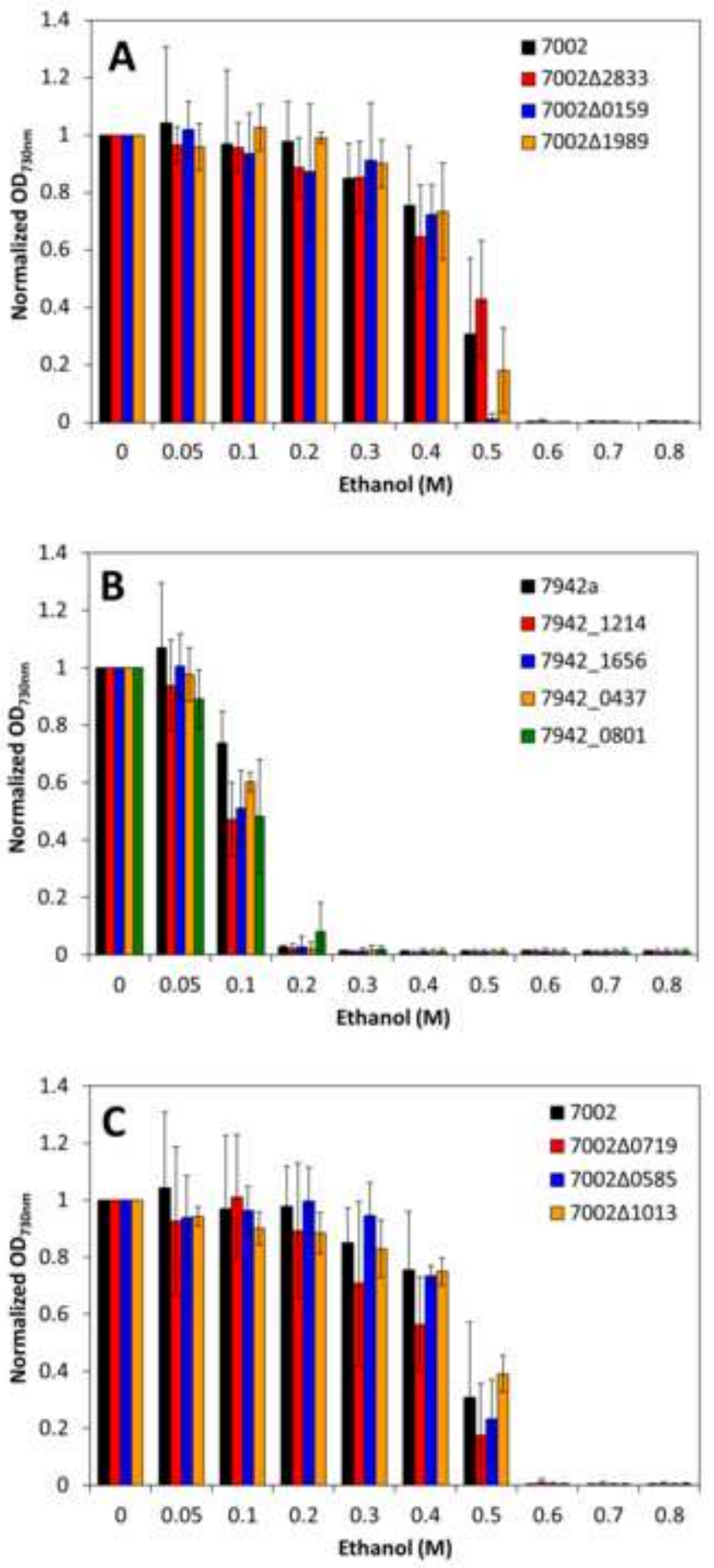